\title{
Sex disparity in acute ischemic stroke outcomes in Korea
}

Byung Cheol Gwak, MD'; Ga Yeon Kim, MD'; Hyo Ji Park, BS²; Su Min Kwon, BS²; Seung II O, BS ${ }^{2}$; Dae-Hyun Kim, MD, PhD'; Jin-Heon Jeong, $\mathrm{MD}^{1,2,3}$; Jae-Kwan Cha, MD, PhD'

'Department of Neurology, Dong-A University Hospital, Busan, Republic of Korea

${ }^{2}$ Stroke Center, Dong-A University Hospital, Busan, Republic of Korea

${ }^{3}$ Department of Intensive Care Medicine, Dong-A University Hospital, Busan, Republic of Korea \\ Care}

ORIGINAL ARTICLE

Received: October 29, 2019

Revised: December 5, 2019

Accepted: December 9, 2019

Corresponding Author:

Jae-Kwan Cha, MD, PhD

Department of Neurology, Dong-A

University Hospital, 26

Daesingongwon-ro, Seo-gu, Busan

49201, Republic of Korea

Tel: +82-51-240-5266

Fax: +82-51-244-8338

E-mail: nrcjk65@gmail.com

Background: It is unclear whether women diagnosed with acute ischemic stroke (AIS) have worse outcome after adjusting for several confounding factors such as age, initial stroke severity, and risk factors. In this study, we investigated sex disparities in long-term functional outcome after AIS.

Methods: We recruited patients with AIS prospectively registered in the Clinical Research Collaboration for Stroke in Korea database of Dong-A University Stroke Center between 2015 and 2018. We reviewed the patients' clinical demographics, living type (alone or cohabitating), laboratory and radiological findings, stroke severity, stroke subtype, and cardiovascular risk profile. We compared the long-term functional outcomes between men and women using the modified Rankin Scale score at 90 days and 1 year after AIS.

Results: A total of 2,711 patients with AIS were enrolled in this study. Women comprised 38.9\% $(1,055)$ of all participants. Compared with men, women were significantly older $(72.7 \pm 11.6$ vs.65.6 $\pm 12.2, P<0.01)$, showed more severe neurologic deficits (median National Institutes of Health Stroke Scale, 5 vs. $4, P<0.01)$, and had a higher rate of living alone $(57.1 \%$ vs. $42.9 \%, P<0.01)$ and a higher prevalence of poor functional outcome at 90 days and 1 year after AIS. However, differences in history of statin use, hospital arrival time, and thrombolysis between the two sexes were not observed. After adjusting for several confounding factors, differences in initial neurologic deficits or long-term functional outcomes between sexes were not observed.

Conclusion: This study demonstrated the absence of sex disparities in the status of medical attention for thrombolysis.

Keywords: Stroke; Sex; Marital status; Treatment outcome

\section{INTRODUCTION}

Stroke is one of the leading causes of death and accounts for a significant burden not only in Western countries $[1,2]$ but also in Asian countries including Korea [3]. Several studies have shown that women have a worse prognosis than men after acute ischemic stroke (AIS) [4-7]. The worse outcome in women might be relat- ed to their advanced age $[6,8,9]$, significant prevalence of atrial fibrillation (AF) $[4,8]$, significantly severe initial neurologic deficit $[4,5]$, and limited medical attention $[4,5,10-12]$ including thrombolysis. Inconsistent results [8,13-15] were observed regarding the role of sex disparity in the prognosis after AIS. The results may vary among different ethnicities. In Japan, women initially showed a severe neurologic deficit and poor long-term out-

(C) 2019 The Korean Neurocritical Care Society

This is an Open Access article distributed under the terms of the Creative Commons Attribution Non-Commercial License (http://creativecommons.org/licenses/by-nc/4.0/) which permits unrestricted noncommercial use, distribution, and reproduction in any medium, provided the original work is properly cited. 
come after AIS [2]. However, more significant differences in social structure and health care for stroke patients are observed in Korea compared with other countries. Therefore, a comprehensive study is required to determine the presence of sexual disparities in initial neurological severity and long-term functional outcome in Korea.

This investigation primarily aimed to evaluate whether sex disparity influenced the outcomes of AIS in Korea after adjusting for patients' clinical demographics, socioeconomic status, vascular risk factors, and the status of medical attention for thrombolysis based on the Clinical Research Collaboration for Stroke in Korea (CRCS-K) prospective registry [16] data involving a single stroke center.

\section{METHODS}

We investigated patients with AIS prospectively enrolled in the CRCS-K Registry of Dong-A University Stroke Center from 2015 to 2018. We reviewed the patients' clinical demographics, living types (living alone or cohabitating), vascular risk factors, and laboratory and radiological findings. All participants' baseline National Institutes of Health Stroke Scale (NIHSS) scores were evaluated by stroke neurologists. Stroke subtypes were determined based on the Trial of Org 10172 in Acute Stroke Treatment classification [17]. To determine the differences in the status of medical attention for thrombolysis between men and women, we investigated the patients' hospital arrival time and performance of intervention (intravenous tissue plasminogen activator [IV t-PA] and/ or mechanical thrombectomy). We compared the above various parameters between sexes.

The functional outcomes of survivors determined using the Modified Rankin Scale (mRS) score were followed up 90 days later and 1 year after stroke onset. The $\mathrm{mRS}$ scores were classified as follows: $\leq 2$ (good functional outcome) and $>2$ (poor functional outcome). These assessments were performed via telephone or face-to-face interview at the outpatient clinic. This study was approved by the local ethics committee (DAUHIRB-17-149). Written informed consent by the patients was waived due to a retrospective nature of our study.

\section{Statistical analysis}

The clinical characteristics of the patients were summarized, and the specific subgroups were described using descriptive statistics. The categorical variables of the groups were compared using Fisher's exact test or Pearson's chi-square test, while Student's $t$ test and Mann-Whitney $U$ test were used to compare the continuous variables of the groups. The odds ratios (ORs) for the comparison of two groups were summarized with $95 \%$ confidence intervals (CIs) and $P$ values using logistic regression analysis. To evaluate the association between the independent factors and the longterm functional outcomes after AIS, a multivariate model was created using a backward elimination method, and the probability threshold for removal was set at 0.10 . The ORs were also adjusted for the factors that affected the response variable. $P$ value less than 0.05 was considered statistically significant. Statistical analyses were performed using the SPSS ver. 21 (IBM Co., Armonk, NY, USA).

\section{RESULTS}

During the observation periods, 2,702 patients with AIS were enrolled in this study, with women comprising $38.9 \%$ (1,055 patients) of all participants. The mean age was $68.4 \pm 12.4$ years, and the median NIHSS score was 4 . The baseline variables stratified according to sex are summarized in Table 1 . Women were significantly older $(72.7 \pm 11.6$ vs. $65.6 \pm 12.22, P<0.01)$ and more often lived alone ( $57.1 \%$ vs. $42.9 \%, P<0.01)$ than men with AIS. Women showed a significantly higher prevalence of AF and hypertension and a lower prevalence of smoking and previous history of coronary artery diseases than men. Women showed significantly higher NIHSS score $(5.9 \pm 5.9$ vs. $7.1 \pm 6.7, P<0.01)$ than men with AIS. However, after adjusting for several confounding factors (living type, age, acute management, risk factors, and stroke subtype), women (OR, 1.25; 95\% CI, 0.97 to 1.62 ; $P=0.09)$ initially showed no significantly severe neurologic deficit after AIS (Supplementary Table 1). A significant difference between sexes in onset-to-door time, based on the use of IV t-PA and mechanical thrombectomy data, was not observed.

Functional outcomes of men and women are shown in Table 2. Women showed a higher prevalence of poor functional outcome at 90 days and 1 year than men after AIS. Age (OR, 1.06; 95\% CI, 1.05 to 1.06 ; $P<0.01)$, living alone (OR, 1.36; $95 \% \mathrm{CI}, 1.06$ to $1.75 ; P=0.01$ ), previous history of $\mathrm{AF}$ ( $\mathrm{OR}, 1.68 ; 95 \% \mathrm{CI}, 1.10$ to 2.56 ; $P=0.02)$, diabetes mellitus ( $\mathrm{OR}, 1.18$; $95 \% \mathrm{CI}, 0.99$ to 1.42 ; $P=0.07)$, previous history of cerebrovascular accident (OR, 1.44; 95\% CI, 1.17 to $1.77 ; P<0.01$ ), and no previous history of statin use (OR, 1.51 ; $95 \% \mathrm{CI}, 1.20$ to $1.90 ; P<0.01)$ were the independent prognostic factors for AIS. However, female sex (OR, 1.10; 95\% CI, 0.89 to 1.36 ; $P=0.37$ ) showed no independent significance for the poor functional outcomes after AIS. Similar results were reported 1 year after AIS (Table 3). The distribution of baseline characteristics and risk factors differed according to sex, but when comparing the functional outcomes between sexes in the same group, significant differences in variables except living alone 
Table 1. Differences in baseline characteristics between men and women

\begin{tabular}{|c|c|c|c|}
\hline Variable & Men $(n=1,656)$ & Women $(n=1,055)$ & $P$ value \\
\hline Age (yr) & $65.6 \pm 12.2$ & $72.7 \pm 11.6$ & $<0.01$ \\
\hline \multicolumn{4}{|l|}{ Living types } \\
\hline Living alone & $226(13.6)$ & $301(28.5)$ & $<0.01$ \\
\hline Cohabitating & $1,430(86.4)$ & $754(71.5)$ & \\
\hline \multicolumn{4}{|l|}{ Risk factors } \\
\hline Hypertension & $981(59.2)$ & $710(67.3)$ & $<0.01$ \\
\hline Diabetes mellitus & $508(30.7)$ & $312(29.6)$ & 0.54 \\
\hline Current or previous history of smoking & $707(42.7)$ & $68(6.4)$ & $<0.01$ \\
\hline Previous history of coronary artery disease & $240(14.5)$ & $123(11.7)$ & 0.04 \\
\hline Previous history of cerebrovascular disease & $325(19.6)$ & $208(19.7)$ & 0.95 \\
\hline Previous history of atrial fibrillation & $331(20.0)$ & $316(30.0)$ & $<0.01$ \\
\hline History of statin use & $284(17.1)$ & $191(18.1)$ & 0.52 \\
\hline Time delay from hospital arrival time, median (IOR) & $546(160-1,486)$ & $544(179-1,390)$ & 0.62 \\
\hline Time delay from hospital arrival time, range & $7-11,408$ & $12-11,230$ & \\
\hline Arrival at the hospital $4.5 \mathrm{hr}$ within onset & $570(34.4)$ & $340(32.2)$ & 0.24 \\
\hline Use of intravenous tissue plasminogen activator & $337(24.9)$ & $196(22.3)$ & 0.16 \\
\hline Door-to-needle time, median (IQR) & $30(23-39)$ & $29(23-38)$ & 0.41 \\
\hline Door-to-needle time, range & $10-124$ & $11-290$ & \\
\hline Mechanical thrombectomy & $140(8.5)$ & $97(9.2)$ & 0.51 \\
\hline Door-to-puncture time, median (IQR) & $103(82-121)$ & $104(80-123)$ & 0.99 \\
\hline Door-to-puncture time, range & $16-445$ & $35-1,049$ & \\
\hline NIHSS score at admission & $5.9 \pm 5.9$ & $7.1 \pm 6.7$ & $<0.01$ \\
\hline \multicolumn{4}{|l|}{ Stroke subtype } \\
\hline Large artery atherosclerosis & $629(38.4)$ & $331(31.6)$ & $<0.01$ \\
\hline Cardioembolism & $322(19.6)$ & $321(30.7)$ & \\
\hline Small-vessel occlusion & $306(18.7)$ & $182(17.4)$ & \\
\hline Stroke of other determined etiologies & $48(2.9)$ & $15(1.4)$ & \\
\hline Stroke of undetermined etiology & $335(20.4)$ & $198(18.9)$ & \\
\hline
\end{tabular}

Values are presented as mean \pm SD or number (\%).

IQR, interquartile range; NIHSS, National Institutes of Health Stroke Scale.

Table 2. Sex differences in functional outcome after acute stroke

\begin{tabular}{lrcc}
\hline Variable & $\begin{array}{c}\text { Men } \\
(n=1,656)\end{array}$ & $\begin{array}{c}\text { Women } \\
(n=1,055)\end{array}$ & Pvalue \\
\hline $\begin{array}{l}\text { mRS score at 90 days } \\
\text { Good functional outcome (0-2) }\end{array}$ & $1,060(64.1)$ & $552(52.7)$ & $<0.01$ \\
$\begin{array}{l}\text { Poor functional outcome (3-6) } \\
\text { mRS score at 1 year }\end{array}$ & $594(35.9)$ & $496(47.3)$ & \\
$\begin{array}{l}\text { Good functional outcome (0-2) } \\
\text { Poor functional outcome (3-6) }\end{array}$ & $821(64.5)$ & $432(53.5)$ & $<0.01$ \\
\end{tabular}

Values are presented as number (\%).

mRS, modified Rankin Scale.

(Supplementary Table 2) were not observed. As shown in Fig. 1, poor functional outcome was observed 90 days after AIS according to age and sex, with a similar prevalence across men and women of all ages except women aged greater than 80 years, who showed a significantly higher prevalence (Supplementary Table 3). Howev- er, after adjusting for several confounding factors, women aged greater than 80 years showed no significant incidence of poor functional outcomes after AIS (OR, 1.39; $95 \% \mathrm{CI}, 0.84$ to 2.29; $P=0.20)$ (Fig. 1).

\section{DISCUSSION}

In this study, we demonstrated that women had a substantially more severe neurologic deficit and a worse outcome at 90 days and 1 year after AIS than men. However, after adjusting for several confounding factors, female sex was not a significant contributing factor to severe initial neurologic deficit and worse long-term outcome after AIS in Korea.

Generally, female sex is an independent factor associated with worse outcome after AIS [4-7]. However, according to other studies, the worse outcome in women was associated with their age, 
Table 3. Multiple logistic regression analysis regarding the predictors of poor functional outcome at 90 days and 1 year after stroke onset

\begin{tabular}{|c|c|c|c|c|c|c|}
\hline \multirow{2}{*}{ Variable } & \multicolumn{3}{|c|}{90 days $\mathrm{mRS}$ score } & \multicolumn{3}{|c|}{1 year mRS score } \\
\hline & $\mathrm{OR}$ & $95 \% \mathrm{Cl}$ & $P$ value & $\mathrm{OR}$ & $95 \% \mathrm{Cl}$ & $P$ value \\
\hline Women & 1.10 & $0.89-1.36$ & 0.37 & 1.08 & $0.85-1.38$ & 0.54 \\
\hline Living alone & 1.50 & $1.21-1.85$ & $<0.01$ & 1.36 & $1.06-1.75$ & 0.01 \\
\hline Age (yr) & 1.06 & $1.05-1.06$ & $<0.01$ & 1.07 & $1.06-1.08$ & $<0.01$ \\
\hline \multicolumn{7}{|l|}{ Risk factors } \\
\hline Diabetes mellitus & 1.18 & $0.99-1.42$ & 0.07 & 1.26 & $1.02-1.56$ & 0.04 \\
\hline Smoking (ref=no smoking) & & & 0.57 & & & 0.10 \\
\hline Current smoking status & 1.12 & $0.89-1.42$ & 0.34 & 1.33 & $1.01-1.75$ & 0.04 \\
\hline Previous history of smoking status & 1.11 & $0.86-1.44$ & 0.43 & 1.24 & $0.92-1.68$ & 0.16 \\
\hline Previous history of coronary artery disease & 1.18 & $0.92-1.50$ & 0.20 & 1.39 & $1.05-1.85$ & 0.02 \\
\hline Previous history of cerebrovascular disease & 1.44 & $1.17-1.77$ & $<0.01$ & 1.19 & $0.93-1.52$ & 0.17 \\
\hline Previous history of atrial fibrillation & 1.55 & $1.06-2.25$ & 0.02 & 1.68 & $1.10-2.56$ & 0.02 \\
\hline Previous history of statin use (ref=yes) & 1.51 & $1.20-1.90$ & $<0.01$ & 1.61 & $1.22-2.12$ & $<0.01$ \\
\hline Stroke subtype (ref=small-vessel occlusion) & & & $<0.01$ & & & $<0.01$ \\
\hline Large artery atherosclerosis & 1.99 & $1.55-2.56$ & $<0.01$ & 2.15 & $1.58-2.92$ & $<0.01$ \\
\hline Cardioembolism & 1.80 & $1.17-2.77$ & $<0.01$ & 2.12 & $1.30-3.47$ & $<0.01$ \\
\hline Stroke of other determined etiologies & 1.60 & $0.79-3.24$ & 0.20 & 3.07 & $1.35-6.94$ & $<0.01$ \\
\hline Stroke of undetermined etiology & 1.45 & $1.09-1.93$ & 0.01 & 1.76 & $1.25-2.48$ & $<0.01$ \\
\hline
\end{tabular}

mRS, modified Rankin Scale; OR, odds ratio; $\mathrm{Cl}$, confidence interval.

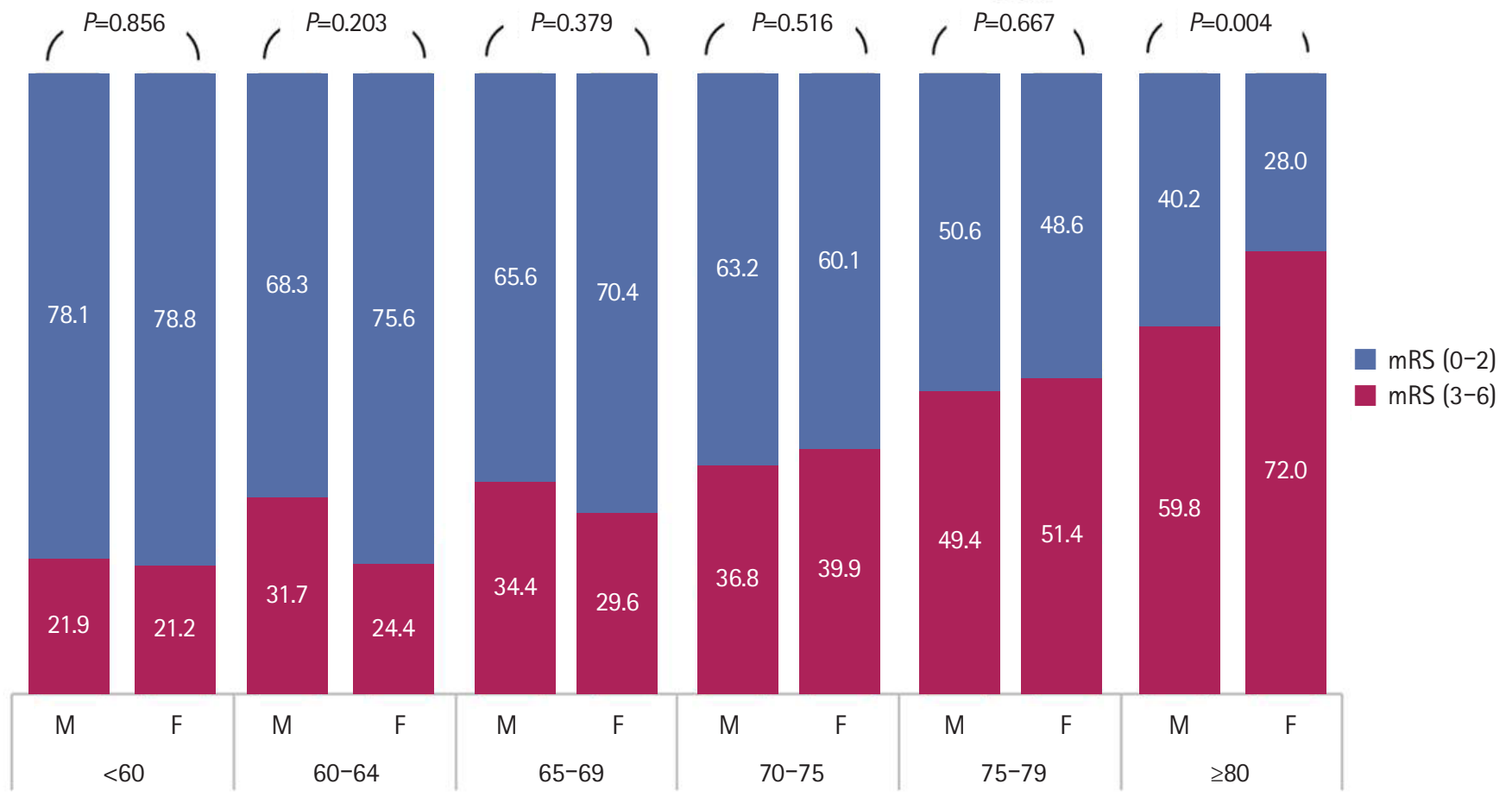

Fig. 1. Distribution of poor functional outcome at 90 days after the diagnosis of acute ischemic stroke by age and sex in the total population. Poor functional outcome (modified Rankin Scale [mRS] score $>2$ ). Any significant difference in poor functional outcome after acute ischemic stroke between both sexes in 80 years or older population (odds ratio, 1.39; 95\% confidence interval, 0.84 to 2.29; $P=0.20$ ) (Supplementary Table 3) after adjusting for age, National Institutes of Health Stroke Scale score, living type, hospital arrival time, mechanical thrombectomy, previous history of statin use, previous history of atrial fibrillation, previous history of coronary artery disease, and stroke subtypes. 
significant prevalence of AF, living alone, poor medical attention before admission, and higher initial NIHSS score [8,13-15].

In this study, women were approximately 7 years older with a higher prevalence of living alone than men, which is a common trend worldwide [4-7]. Thus, women had poor control of risk factors before being diagnosed with AIS $[18,19]$ and received limited medical attention before arriving at the emergency room $[4,5]$ for thrombolysis [10-12]. However, we demonstrated that statin use was not different between sexes. Moreover, disparity between sexes was not observed in hospital arrival time, the use of IV t-PA, and mechanical thrombectomy after AIS. Almost all previous studies reported in western countries and Japan demonstrated that poor medical attention in women before and after AIS contributed significantly to poor long-term outcome. In Korea, as reported previously, well-developed medical insurance and public transportation for emergent patients were associated with the prevention of poor functional outcome in women after AIS [7]. Notably, in this study, a significant difference in age-specific prognosis was not observed between sexes, different from a previous study that showed significantly worse outcomes after AIS in patients aged 85 years and above [8].

Living alone has been considered a critical factor for worse outcome $[20,21]$. In this study, although living alone was one of the key factors associated with worse outcome in the whole population after AIS, it was not restricted to women (Supplementary Table 4). In this study, the rate of living alone in women was twice that of men. Notably, the mean age of women living alone was significantly higher than that of men. We presumed that bereavement might have contributed to single living because of the substantially longer lifespan in women. In contrast, living alone in men might be related to other causes such as divorce, home loss, and domestic discord caused by financial crisis rather than natural death of their spouse. A previous study demonstrated that living alone by men aged less than 70 years had a significantly higher impact on the outcomes after AIS compared with women. The study presumed that men were more dependent on spousal encouragement in seeking medical attention for cardiovascular diseases compared with women, and men living alone have higher chances of consuming an unhealthy diet and exhibiting poor health behaviors such as smoking and heavy drinking than women living alone or cohabitating with others [21-23]. Therefore, single men may manifest a negative impact after AIS, similar to women. Hence, further studies are required to validate this hypothesis.

The previous studies showed worse outcomes in women after AIS after adjusting for age and confounding risk factors. They suggested that a rapid decrease of endogenous estrogen diminished its anti-inflammatory and neuroprotective effects [24] and increased the susceptibility of cells to programmed cell death [25]. Furthermore, in Korea, a unique lifestyle based on a patriarchal-feudalistic chauvinism and Confucianism might contribute to the occurrence of worse outcomes in women after AIS [7,26]. However, the social status of women in Korea has changed dramatically in several aspects due to increased employment rate, improvement of subjective personal health status, and the role of women in institutionalization [27]. Due to the changes mentioned above, it is likely that women have better improved their vulnerability to AIS in Korea compared with the previous reports.

Despite the several significant results, the study has some limitations. First, this was a single-center study, and the findings do not represent nationwide data. Second, we used $\mathrm{mRS}$ as a parameter of long-term functional outcome after AIS, which does not represent all the sequelae. Therefore, a variety of tools are required to measure mood, function, and quality of life among women diagnosed with AIS.

This study showed no significant differences between sexes in Korea in initial severity and long-term functional outcome after AIS, in contrast to a previous report.

\section{ARTICLE INFORMATION}

\section{Conflict of interest}

Dr. JH Jeong is an editorial board member of the journal but was not involved in the peer reviewer selection, evaluation, or decision process of this article. There are no other potential conflicts of interest relevant to this article to declare.

\section{ORCID}

Byung Cheol Gwak, https://orcid.org/0000-0001-8130-4484

Ga Yeon Kim, https://orcid.org/0000-0003-4314-7646

Hyo Ji Park, https://orcid.org/0000-0002-8250-1428

Su Min Kwon, https://orcid.org/0000-0002-3830-4443

Seung Il O, https: / / orcid.org/0000-0002-3742-7070

Dae-Hyun Kim, https://orcid.org/0000-0001-9761-7792

Jin-Heon Jeong, https://orcid.org/0000-0002-5878-9206

Jae-Kwan Cha, https://orcid.org/0000-0002-1049-5196

\section{Author contributions}

Conceptualization: DHK. Data curation \& Formal analysis: SMK and SIO. Investigation: HJP. Supervison: JKC. Visualization \& Writing-original draft: BCG and GYK. Writing-review editing: JHJ.

\section{Additional information}

The supplement is available at https://doi.org/10.18700/jnc. 190108. 


\section{REFERENCES}

1. National Center for Health Statistics. Health, United States, 2004 with chartbook on trends in the health of Americans. Hyattsville: US Government Printing Office; 2004.

2. Adamson J, Beswick A, Ebrahim S. Is stroke the most common cause of disability? J Stroke Cerebrovasc Dis 2004;13:171-7.

3. Hong KS, Bang OY, Kang DW, Yu KH, Bae HJ, Lee JS, et al. Stroke statistics in Korea: part I. Epidemiology and risk factors: a report from the Korean Stroke Society and clinical research center for stroke. J Stroke 2013;15:2-20.

4. Kim JS, Lee KB, Roh H, Ahn MY, Hwang HW. Gender differences in the functional recovery after acute stroke.J Clin Neurol 2010;6:183-8.

5. Maeda K, Toyoda K, Minematsu K, Kobayashi S; Japan Standard Stroke Registry Study Group. Effects of sex difference on clinical features of acute ischemic stroke in Japan. J Stroke Cerebrovasc Dis 2013;22:1070-5.

6. Di Carlo A, Lamassa M, Baldereschi M, Pracucci G, Basile AM, Wolfe CD, et al. Sex differences in the clinical presentation, resource use, and 3-month outcome of acute stroke in Europe: data from a multicenter multinational hospital-based registry. Stroke 2003;34:1114-9.

7. Gall SL, Donnan G, Dewey HM, Macdonell R, Sturm J, Gilligan A, et al. Sex differences in presentation, severity, and management of stroke in a population-based study. Neurology 2010;74:975-81.

8. Holroyd-Leduc JM, Kapral MK, Austin PC, Tu JV. Sex differences and similarities in the management and outcome of stroke patients. Stroke 2000;31:1833-7.

9. Roquer J, Campello AR, Gomis M. Sex differences in first-ever acute stroke. Stroke 2003;34:1581-5.

10. Messé SR, Khatri P, Reeves MJ, Smith EE, Saver JL, Bhatt DL, et al. Why are acute ischemic stroke patients not receiving IV tPA? Results from a national registry. Neurology 2016;87:1565-74.

11. Reid JM, Dai D, Gubitz GJ, Kapral MK, Christian C, Phillips SJ. Gender differences in stroke examined in a 10-year cohort of patients admitted to a Canadian teaching hospital. Stroke 2008;39:1090-5.

12. Foerch C, Misselwitz B, Humpich M, Steinmetz H, Neumann-Haefelin T, Sitzer M, et al. Sex disparity in the access of elderly patients to acute stroke care. Stroke 2007;38:2123-6.

13. Kapral MK, Fang J, Hill MD, Silver F, Richards J, Jaigobin C, et al. Sex differences in stroke care and outcomes: results from the Registry of the Canadian Stroke Network. Stroke 2005;36:80914.

14. Kelly-Hayes M, Beiser A, Kase CS, Scaramucci A, D’Agostino
RB, Wolf PA. The influence of gender and age on disability following ischemic stroke: the Framingham study. J Stroke Cerebrovasc Dis 2003;12:119-26.

15. Lai SM, Duncan PW, Dew P, Keighley J. Sex differences in stroke recovery. Prev Chronic Dis 2005;2:A13.

16. Lee KJ, Kim BJ, Kim DE, Ryu WS, Han MK, Kim JT, et al. Nationwide estimation of eligibility for endovascular thrombectomy based on the DAWN trial.J Stroke 2018;20:277-9.

17. Adams HP Jr, Bendixen BH, Kappelle LJ, Biller J, Love BB, Gordon DL, et al. Classification of subtype of acute ischemic stroke. Definitions for use in a multicenter clinical trial. TOAST. Trial of Org 10172 in Acute Stroke Treatment. Stroke 1993;24:3541.

18. Simpson CR, Wilson C, Hannaford PC, Williams D. Evidence for age and sex differences in the secondary prevention of stroke in Scottish primary care. Stroke 2005;36:1771-5.

19. Glader EL, Stegmayr B, Norrving B, Terént A, Hulter-Asberg K, Wester PO, et al. Sex differences in management and outcome after stroke: a Swedish national perspective. Stroke 2003; 34:1970-5.

20. Reeves MJ, Prager M, Fang J, Stamplecoski M, Kapral MK. Impact of living alone on the care and outcomes of patients with acute stroke. Stroke 2014;45:3083-5.

21. Redfors P, Isaksén D, Lappas G, Blomstrand C, Rosengren A, Jood $\mathrm{K}$, et al. Living alone predicts mortality in patients with ischemic stroke before 70 years of age: a long-term prospective follow-up study. BMC Neurol 2016;16:80.

22. Kristofferzon ML, Löfmark R, Carlsson M. Myocardial infarction: gender differences in coping and social support. J Adv Nurs 2003;44:360-74.

23. Hanna KL, Collins PF. Relationship between living alone and food and nutrient intake. Nutr Rev 2015;73:594-611.

24. McCullough LD, Hurn PD. Estrogen and ischemic neuroprotection: an integrated view. Trends Endocrinol Metab 2003; 14:228-35.

25. Bushnell CD, Hurn P, Colton C, Miller VM, del Zoppo G, Elkind MS, et al. Advancing the study of stroke in women: summary and recommendations for future research from an NINDS-Sponsored Multidisciplinary Working Group. Stroke 2006;37:2387-99.

26. Son HC. The Confucian understanding of women. Cathol Philos 2005; 7:109-47.

27. Statics Korea. Press releases: employment and labour [Internet]. Daejeon (KR): Statics Korea; c1996-2019 [cited 2019 Dec 16]. Available from: http://kostat.go.kr/portal/eng/pressReleases/5/1/index.board. 